\title{
Uma nova combinação em Deltocephalinae (Hemiptera, Cicadellidae) ${ }^{1}$
}

\author{
Keti Maria Rocha Zanol ${ }^{2}$
}

${ }^{1}$ Contribuição ${ }^{0} 1497$ do Departamento de Zoologia, Universidade Federal do Paraná.

${ }^{2}$ Departamento de Zoologia, Universidade Federal do Paraná. Caixa Postal 19020, 81531-980 Curitiba-PR, Brasil.

${ }^{3}$ Bolsista do CNPq. kzanol@ufpr.br.

\begin{abstract}
A new combination in Deltocephalinae (Hemiptera, Cicadellidae). Amplicephalus quadrinotatus (DeLong, 1984) comb. nov. (formerly in Frequenamia). The species is redescribed and illustrated.

Keywords. Amplicephalus; Deltocephalini; redescription; taxonomy.

Resumo. Uma nova combinação em Deltocephalinae (Hemiptera, Cicadellidae). Amplicephalus quadrinotatus (DeLong, 1984) comb. nov. (antes em Frequenamia). Redescrição e ilustração da espécie são dadas.

Palavras-Chave. Amplicephalus; Deltocephalini; redescrição; taxonomia.
\end{abstract}

Amplicephalus quadrinotatus (DeLong, 1984) comb. nov. (Figs. 1-8)

Frequenamia quadrinotata DeLong, 1984: 115. Localidade-tipo: Colômbia, Camp Curiche.

Frequenamia quadrinota [sic]; Delong, 1984: 119.

Macho. Coroa amarelada com a margem anterior marrom; região frontal com duas manchas quadrangulares marrons; região discal com duas manchas retangulares marrons. Face amarelada. Frontoclípeo manchado de marrom. Anteclípeo marrom. Genas com uma mancha marrom junto aos alvéolos antenais. Pronoto amarelado com manchas marrons. Asas anteriores transparentes com manchas marrons e amarelas; estas formando pequenas células. Venação amarela.

Cabeça mais larga que o pronoto; região frontal levemente voltada para cima e microesculturada; região discal lisa. Sutura coronal ultrapassando a metade do comprimento da coroa. Face mais ou menos ampla e achatada; sutura transclipeal obscura. Anteclípeo de lados paralelos. Genas com reentrância abaixo dos olhos.

Asas anteriores com três células anteapicais fechadas; as células central e interna com veias extranumerárias. Célula braquial e $2^{\mathrm{a}}$ célula discal com veias extranumerárias. Apêndice curto, não alcançando $\mathrm{M}_{3+4}$. Espinulação dos fêmures posteriores $2+2+1$ e das tíbias anteriores $1+4$.

Pigóforo com muitas macrocerdas; ápice serreado. Valva genital trapezoidal. Placas subgenitais triangulares com três macrocerdas. Estilos com apófise digitiforme; ápice bilobado. Edeago tubular com ápice bífido; metade apical alargada e com um par de processos triangulares laterais; fragma fortemente esclerotinizado formando uma aba cobrindo dorsalmente a base do edeago. Conetivo linear com ápice fundido.

\section{Comprimento total. $4,5 \mathrm{~mm}$}

Fêmea. Desconhecida.

Material examinado. "Holotype Frequadrinota [sic] quadrinota [sic] DeLong, Choco Dept., Camp Curiche, Colômbia, 1967 (Ohio State University)."

Comentário. DeLong (1984) descreveu a espécie em Frequenamia, gênero pertencente à tribo Athysanini. Ao examinar o exemplar-tipo, verificaram-se as seguintes características: três células anteapicais fechadas, a central dividida; conetivo linear; edeago com ápice bífido. Por conseguinte, transfere-se a espécie para o gênero Amplicephalus DeLong, 1926, da tribo Deltocephalini. Pelas características apresentadas, enquadra-se no subgênero Amplicephalus (Nanctasus) Linnavuori, 1959.

DeLong (1984), na página 115, denominou de Frequenamia quadrinotata sp. n. e, na página 119, Frequenamia quadrinota sp. n. No presente trabalho, optou-se pela grafia quadrinotata por se achar que o autor estava se referindo às quatro manchas existentes na coroa. Ainda, por engano, escreveu na etiqueta do holótipo "Frequadrinota", gênero este inexistente em Deltocephalinae.

Agradecimento. A Peter W. Kovarik, Ph. D. do Museum of Biological Diversity, Ohio State University, USA pelo empréstimo do holótipo.

\section{REFERÊNCIA}

DeLong, D. M. 1984. New leafhoppers of the "Bahita" group (Homoptera: Cicadellidae: Deltocephalinae) from Central and South America. Brenesia 22: 115-122. 

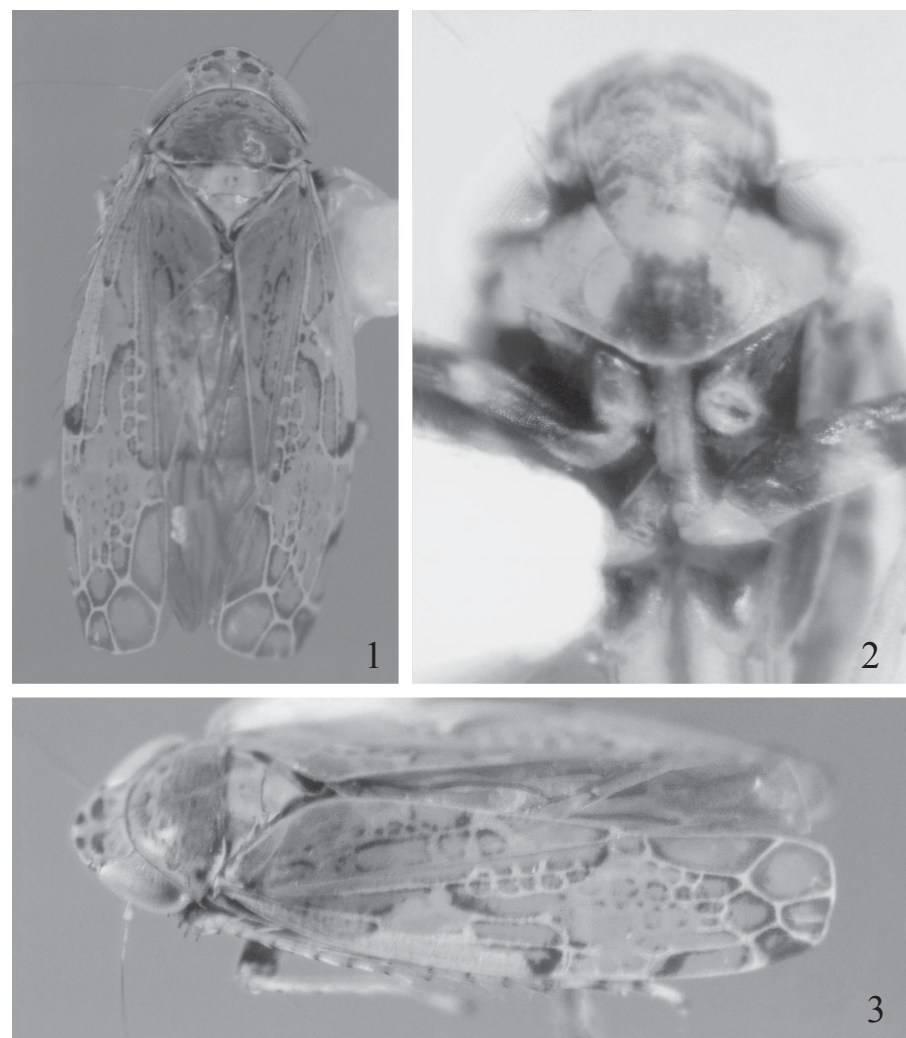

Figs. 1-3. Amplicephalus quadrinotatus (DeLong, 1984) comb. nov. 1. Vista dorsal; 2. Face; 3. Vista látero-dorsal (Holótipo macho).
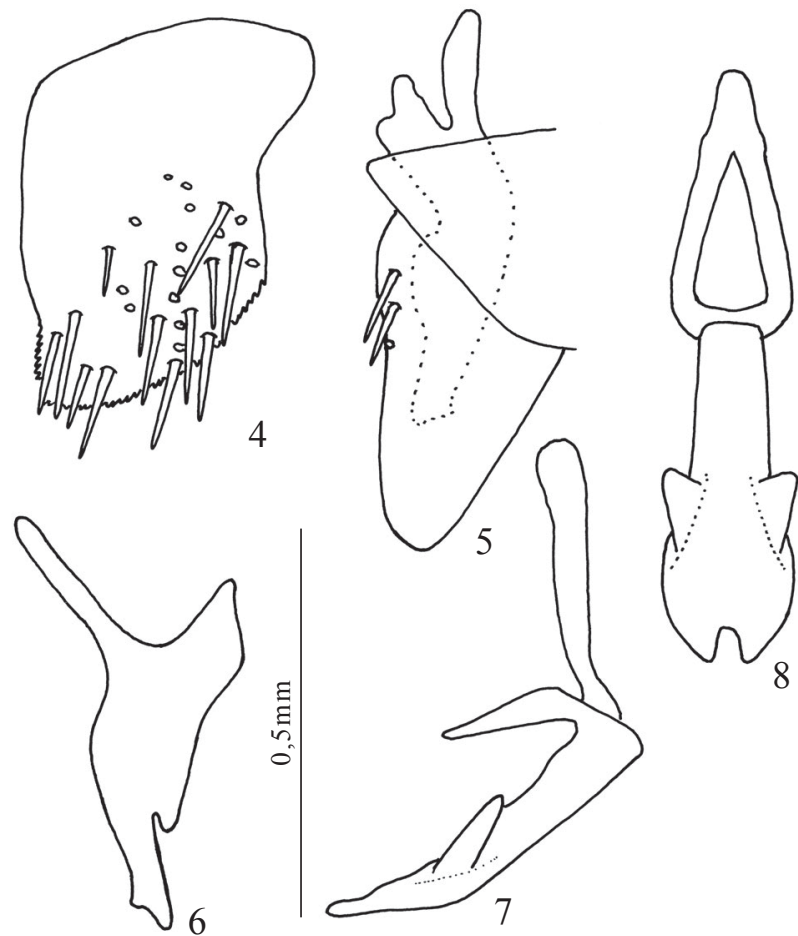

Figs. 4-8. Amplicephalus quadrinotatus (DeLong, 1984) comb. nov. 4. Pigóforo, lateral; 5. Valva genital, placa subgenital e estilo; 6. Estilo; 7. Conetivo e edeago, lateral; 8. Conetivo e edeago, vental (Holótipo macho). 